\title{
The Effects of Selected Aerobic Exercise Modalities on Self Esteem among Female Students
}

\author{
Norlena Salamuddin ${ }^{1}$, Mohd Taib Harun ${ }^{1} \&$ Sanaa Ali Ahmed Al-Rashed ${ }^{2}$ \\ ${ }^{1}$ Universiti Kebangsaan Malaysia, Malaysia \\ ${ }^{2}$ Basra University, Iraq \\ Correspondence: Norlena Salamuddin, Faculty of Education, Universiti Kebangsaan Malaysia, 43600 Bangi, \\ Selangor, Malaysia. E-mail: lena@ukm.my
}

\author{
Received: February 12, 2014 Accepted: February 20, 2014 Online Published: February 28, 2014 \\ doi:10.5539/ass.v10n5p141 \\ URL: http://dx.doi.org/10.5539/ass.v10n5p141
}

\begin{abstract}
Self-esteem is fundamental component in psychological health and is affected with dynamics of physical exercise. This study explore the effects of selected aerobic exercise programs on self esteem and attempts to determine the most effective aerobic exercise program in boosting self-esteem. This study uses the experimental design on a sample of 120 female undergraduate students. The instruments used were the Self-Esteem Scale. Data was analyzed using inferential statistics. t-test conducted shows significant differences in self-esteem score between pretest and posttest in all modalities of aerobic exercise programs. Analysis of variance reveals that there is a significant difference $(\mathrm{F}=81.299, \mathrm{p}<0.01)$ between the four modalities of aerobic exercise programs, and post hoc test shows that combination of step-dance aerobics and weight training program is most effective in increasing self esteem among female students. Results of this study contribute to developing the role of aerobic exercise in improving self esteem. It is also useful in assisting to develop policies and programs that enhance self esteem.
\end{abstract}

Keywords: self-esteem, exercise, aerobics

\section{Introduction}

It is commonly acknowledged that physical activity and exercise have a positive impact on many aspects of health. Besides the many positive physical health benefits of exercise, research has also clearly suggested a positive association between exercise and psychological health and well-being (Plante \& Rodin 1990; Salmon 2000). Physical exercise is one of the most important contributors to overall health of an individual. In addition to its contribution to physical health, recreational exercise activity can contribute sugnificantly to psychological well-being and improvement in self-confidence and self-esteem (Stambulova, Johnson, Lindwall \& Hinic 2004; Fox, 2000). Research has also verified the beneficial effects of exercise on psychological health and well-being across populations (Salmon, 2000). Some researchers believe that self-esteem is the 'psychological variable with the most potential to reflect psychological benefits as a result of regular exercise' (Caruso \& Gill, 1992). As a psychological variable, there is positive correlation between self-esteem (McAuley et al., 2000). For some women, fitness seems to enhance an inner sense of wellbeing and integrity that makes them feel more comfortable about themselves and gives them self-confidence. This newly gained self-confidence with fitness flows into diverse areas of their lives as well (Kenen, 1987). These studies suggest that women who are committed to an active lifestyle enjoy the benefits of improved self-esteem. Eickoff et al (1983) demonstrated that introducing an individual to a regular exercise regime also enhance wellbeing. Female subjects who had been classified in the lower levels of cardiovascular fitness showed beneficial changes in psychological scores associated with the physical self after a 10 week aerobic program. Based on this study, increased self-esteem among some active women is associated with the accomplishment of becoming physically fit and committing oneself to an exercise program.

Other researches indicate that, for some exercisers, self-esteem is linked more specifically to dimensions of body image and appearance enhancement. Markula (1993) found that some aerobics participants overtly connected self-esteem with appearance. Frederick and Shaw (1995) discovered that women feeling 'really good' about themselves after exercising because they are working on their body shape. Richman and Schaffer (2000) concluded that girls and women who participated in sport or physical activity before going to university 
displayed greater levels of self-worth, physical competence, and body image. Notably, non-participation had a negative impact of self-esteem. Improvements in self-esteem through sport participation may be enhanced by feelings of accomplishment and perceptions of improved physical appearance, as well as demonstrating a high degree of commitment to exercise. Certainly there are evidenced which supports the role of sports and physical activity participation in enhancing self-esteem in girls and women (Kenen, 1987; Eickoff et al., 1983; Warrick \& Pierce, 1989). In a study of sixty elite female ice hockey players, Young (1997) found that participation was related to higher self- esteem, confidence, and body image. Similarly, girls who participated in a sports program in Norway reported enhanced levels of confidence, success and mastery. 'Feeling of belongingness' and a sense of 'being seen and confirmed' were also elements of the girls narratives (Lindgren, Patriksson \& Fridlund, 2002). Brady (2005) and, Brady and Khan (2002) suggest that sports for girls plays a significant role in enhancing self-empowerment, self-esteem, and personal freedom. Clearly, self-esteem is quite complex and studies suggest that certain subcomponents contribute to a person's self-esteem, which includes perceived sports competence, physical condition, body image and strength (Scully, Kremer, Meade, Graham \& Dudgeon, 1998).

Researches have also shown that when adults, adolescents, and children undertook an exercise program, self-esteem is enhanced in the process. This article examines how different types of exercise program effects self-esteem of its participants.

\section{Methodology}

The sample for this study was 120 randomly assigned, full time undergraduate female students. The population were female undergraduates who were classified as freshmen, sophomores, juniors and seniors who did not exercise regularly (exercise less than twice a week). Participants were recruited from various faculties and were given a Self Esteem Questionnaire (pre-test) to answer which consist of ten items to assess their self esteem. Through random assignment, sample were divided into four groups; i - walking/jogging, ii - step and dance aerobic iii - step and dance aerobic plus weight training, and, iv - control group. The intervention program is conducted four days per week with sixty minutes per session and lasts for twelve weeks. At the end of twelve weeks, i.e. after the intervention period, participants again were given the Self Esteem Questionnaire (post-test) to answer. Data collected was analysed using quantitative procedures.

\section{Results}

To determine the differences between the pre-test and post-test scores on self-esteem, data were analysed using t-test. The self-esteem questionnaire is based on Rosenberg's Self Esteem (RSE) which is the most widely used measure of global self-esteem within health psychology (Baldwin \& Courneya, 1997; Rosenberg, 1965). Paired sample t-test showed significant differences between pre-test and post-test scores in the self-esteem questionnaire in all groups of the exercise programs. Table 1 shows the results of t-test of self-esteem in walking/jogging group, step-dance aerobics group, step-dance weight training group and control group.

Table 1. Result of t-test between pre- and post-test score for the four exercising groups

\begin{tabular}{ccccccc}
\hline & \multicolumn{3}{c}{ Self Esteem Scores } & \multirow{2}{*}{ Post-test } \\
Exercise program & Mean & SD & Mean & SD \\
\hline Walking/jogging & 33.12 & 1.01 & 12.87 & 1.70 & $7.51^{*}$ \\
Step-dance aerobics & 20.52 & 1.62 & 12.11 & 1.21 & $5.91^{*}$ \\
Step-dance and weight training & 12.73 & 1.33 & 12.09 & 1.51 & $1.65^{*}$ \\
Control & 11.99 & 1.03 & 25.96 & 1.97 & $5.32^{*}$ \\
\hline
\end{tabular}

$* \mathrm{p}<0.05$

For the self-esteem, the higher the score obtained means the more negative is the self-esteem. Results showed that there is a statistically significant decrease from pre-test scores to post=test scores of self-esteem for the following program; walking/jogging program $(\mathrm{t}=7.51, \mathrm{p}<0.05)$ from the pre-test score $(\mathrm{m}=33.12)$ to their post-test score $(\mathrm{m}=12.87)$, step-dance aerobics program $(\mathrm{t}=5.91, \mathrm{p}<0.05)$ from the pre-test score $(\mathrm{m}=20.52)$ to their post-test score $(\mathrm{m}=12.11)$, and, step-dance and weight training program $(\mathrm{t}=1.65, \mathrm{p}<0.05)$ from the pre-test score $(\mathrm{m}=12.73)$ to their post-test score $(\mathrm{m}=12.09)$. This means that self-esteem improved in those subjects that took part in the exercise program. Participants in the control group showed statistically significant increase 
$(\mathrm{t}=5.32, \mathrm{p}<0.05)$ from the pre-test score $(\mathrm{m}=11.99)$ to their post-test score $(\mathrm{m}=25.96)$, showing that after 12 weeks of no exercise, the participants in the control group portrays a more negative self-esteem.

To compare the different effect of the four types of exercise program on self-esteem, analysis of variance (ANOVA) was used. Additionally, to discover which exercise program contributed the most to the observed differences, LSD (least significant difference) was used. Table 2 shows the result of ANOVA for self-esteem.

Table 2. Result of ANOVA for self-esteem

\begin{tabular}{ccccc}
\hline & Sum of Squares & df & Mean Square & F \\
\hline Between groups & 19.11 & 3 & 6.37 & $54.73^{* *}$ \\
Within groups & 13.5 & 116 & 0.116 & \\
Total & 32.61 & 119 & 6.486 & \\
\hline
\end{tabular}

$* * \mathrm{p}<0.01$

The analysis in Table 2 shows that there were significant differences between groups in self-esteem $(\mathrm{F}=54.73$, $\mathrm{p}<0.01)$. LSD post hoc test indicated that there is a significant difference between between the exercise groups from most to least contribution in the following manner; step-dance weight training program, step-dance aerobics program and walking/jogging program.

\section{Discussion}

The findings of this study showed the superiority of step-dance weight training program and step-dance aerobics program in boosting self-esteem. This result could be attributed to the nature of step-dance weight training program and it is a comprehendible compound of three types of exercise; step aerobics, dance aerobics and weight training program. This program has a favourite characteristic in that it blends the elements of aerobics exercise and weight training whereby one is rhythmic and the latter is not. The implications of these findings are that different types of aerobic exercise programs have different effects on self-esteem of undergraduate female students. Step-dance weight training and step-dance aerobics programs contributed the most to the observed differences in self-esteem of undegraduate female students.

According to the Report of the Surgeon General on Physical Activity and Health (1996), aerobics exercise should be supplemented with strength developing exercises at least twice a week. These activities will help build strength, maintain bone density, an, improve balance, coordination and mobility. Strength training when done with regular aerobic exercise, can also have a major effect on an individual's mental and emotional health. Strength training exercise can also reduce depression and boost self-confidence and self-esteem, and improve sense of well-being. This finding corroborates the ideas of Dunton et al (2006) who suggested that exercise programs that is designed to improve self-perceptions may require physical activities that is sufficient to improve cardiovascular fitness and decrease body fat.

Spence et al (2005) states that the benefits of exercise of self-esteem are overstated in the literature. They confirmed that participation in exercise programs does lead to significant increases in self-esteem but from a statistical point of view, the improvements were small. They identified that the type of program and changes in fitness are two significant contributors of self-esteem. The results of their study showed that exercise and lifestyle programs produce small to moderate increases in self-esteem while skill training activities demonstrated no effect on self-esteem. They also found that changes in physical fitness were related to significant increases in self-esteem.

Fox (1999) review on the influence of physical activity on mental well-being acknowledges the growing evidence demonstrating how exercise may be effective in improving the mental well-being of the general public, largely through improved mood and physical self-perception. Fox (1999) further notes the strong evidence to support the use of aerobic and resistance exercise for enhancing mood states, and that the evidence is weaker in support of the use of exercise to improve cognitive function in older adults (as assessed by reaction time). He further suggested several possible mechanisms for the positive effects of exercise on improving mental well being: $\mathrm{i}$ - biochemical - the endorphin effect, ii - physiological - increase muscle reactions, cerebral blood flow and neuro transmitter efficiency, and, iii - psychosocial - improved perception of competence, self-efficacy and confidence about the body and its capabilities. 


\section{Conclusion}

The result of this study shed light on the effects of different modalities od aerobic exercise programs on self-esteem, and identifying the nature of the most effective exercise in improving self-esteem of undergraduate female students. It shows that the result of this study will offer a new view in boosting self-esteem. The findings can also be useful for fitness professionals, who play an important role in physical exercise and health literacy. However, more research is needed to determine the effect of combining aerobic exercise and weight training on mental health and well-being.

\section{References}

Baldwin, M. K., \& Courneya, M. S. (1997). Exercise and self-esteem in breast cancer survivors: An application of the exercise and self-esteem model. Journal of Sport and Exercise Physiology, 19, 347-358.

Boyd, K. R., \& Hrycaiko, D. W. (1997). The effect of physical activity intervention package on the self-esteem of pre-adolescent and adolescent females. Adolescence, 32, 693-707.

Brady, M. (2005). Creating safe spaces and building social assets for young women in the developing world: A new role for sports. Women Studies Quarterly, 33(1-2), 35.

Brady, M., \& Banu-Khan. (2002). Letting Girls Play: The Mathare Youth Sports Association's football program for girls. Unpublished report.

Caruso, C., \& Gill, D. L. (1992). Strengthening physical self-perseption through exercise. Journal of Sport Medicine and Physical Fitness, 32, 416-427.

Daubenmier, J. J. (2005). The relationship of yoga, body awareness, and body responsiveness to self objectification and disordered eating. Psychology of Women Quarterly, 29, 207-212. http://dx.doi.org/10.1111/j.1471-6402.2005.00183.x

Dunton, G. F., Schneider, M., Graham, D. J., \& Cooper, D. M. (2006). Physical activity, fitness, and physical self-concept in adolescent females. Paediatric Exercise Science, 18, 240-251.

Eickoff, J., Thorland, W., \& Ansorge, C. (1983). Selected physiological and psychological effects of aerobic dancing among young adult women. Journal of Sports Medicine, 23, 273-280.

Fox, K. R. (1999). The influence of physical activity on mental well-being. Public Health Nutrition, 2, 411-418. http://dx.doi.org/10.1017/S1368980099000567

Fox, K. R. (2000). The effects of exercise on self-perception and self-esteem. In S. J. H. Biddle, K. R. Fox, \& S. H. Boutcher (Eds.), Physical Activity and Psychological Well Being (pp. 88-117). London: Routledge.

Frederick, C. J., \& Shaw, S. M. (1995). Body image as a leisure constraint: Examining the experience of aerobic $\begin{array}{llllll}\text { exercise classes for young women. Leisure } & \text { Science, } 17, \text { 53. }\end{array}$ http://dx.doi.org/10.1080/01490409509513244

General, S. (1996). A report of the Surgeon General Physical Activity and Health at a glance. U.S. Department of Health and Human Services.

Kenen, R. (1987). Double messages, double images: Physical Fitness, Self-concepts and Women in Exercise Classes. Journal of Physical Education, Recreation and Dance, 58, 76-79. http://dx.doi.org/10.1080/07303084.1987.10609581

Lindgren, E. C., Patriksson, G., \& Fridlund, B. (2002). Benefits of a self strengthening programme among young female athletes. Unpublished disertation.

Markula, P. (1993). Looking good, feeling good: Strengthening mind and body in aerobics. In L. Laine (Ed.), On the Fringe of Sport (pp. 93-99). Germany, Sankt Augustin: Akademia Verlag.

McAuley, E., Blissmer, B., Katula, J., Duncan, T. E., \& Mihalko, S. L. (2000). Physical activity and self-efficacy realtionships in older adults: A randomized controlled trial. Annals of Behavioral Medicine, 22(2), 131-139. http://dx.doi.org/10.1007/BF02895777

Plante, T. G., \& Rodin, J. (1990). Physical fitness and enhanced psychological health. Currents Psychology: Research \& Reviews, 9(1), 3-24. http://dx.doi.org/10.1007/BF02686764

Richman, E., \& Schaffer, D. (2000). If you let me play sports: How might sport participation influence self-esteem of adolescent females? Psychology of Women Quarterly, 24(2), 189-199. http://dx.doi.org/10.1111/j.1471-6402.2000.tb00200.x 
Rosenberg, M. (1965). Society and the Adolescent Self-Image. Princeton, NJ: University Press.

Salmon, P. (2000). Effects of physical exercise on anxiety, depression, and sensitivity to stress: A unifying theory. Clinical Psychology Review, 21, 33-61. http://dx.doi.org/10.1016/S0272-7358(99)00032-X

Scully, D., Kremer, J., Meade, M., Graham, R., \& Dudgeon, K. (1998). Physical exercise and psychological well-being: A critical review. British Journal of Sports Medicine, 32, 111-120. http://dx.doi.org/10.1136/bjsm.32.2.111

Spence, J. C., McGannon, K. R., \& Poon, P. (2005). The effect of exercise on global self-esteem: A quantitative review. Exercise Psychology, 27, 311-314.

Stambulova, N., Johnson, U., Lindwall, M., \& Hinic, H. (2004). Athletes perceived health: A 'benefit' or a 'cost' of a multiyear sport participation? Unpublished dissertation, Halmastd University.

Warrick, W. F., \& Pierce, W. D. (1989). Women's bodies, self-perception and physical activity: A naturalistic study of women's participation in aerobics classes. The ACHPER National Journal, 125, 8-12.

Young, K. (1997). Women, sport and physicality: Preliminary findings from a Canadian Study. International Review for the Sociology of Sport, 32(3), 297-305. http://dx.doi.org/10.1177/1012690297032003006

\section{Copyrights}

Copyright for this article is retained by the author(s), with first publication rights granted to the journal.

This is an open-access article distributed under the terms and conditions of the Creative Commons Attribution license (http://creativecommons.org/licenses/by/3.0/). 